\title{
The Effect of Formaldehyde on the Shape of Bacterial Flagella
}

\author{
BY E. LEIFSON \\ Stritch School of Medicine and Graduate School, Loyola University, \\ Chicago, Illinois, U.S.A.
}

(Received 25 November 1960)

\section{SUMMARY}

Addition of formalin ( $40 \%$ formaldehyde) to a concentration of 5-10\% (v/v) to a bacterial culture before flagellar staining may change the shape of the flagella as seen in the stained preparation. With many bacteria, if not a majority, the formalin has no effect on the flagellar shape. The coiled, the straight, the small-amplitude and the typical undulant flagellar shapes evidently are mainly due to formalin fixation. The effect of formalin on flagellar shape may have taxonomic significance and should be recorded. Formalin fixation is advantageous in flagellar staining in that it kills the bacteria and makes for nicer preparations, especially when the bacteria are capsulated.

\section{INTRODUCTION}

For the past decade the author has routinely added 5-10\% (v/v) of formalin (40\% formaldehyde solution) to all bacterial cultures before washing and flagellar staining. The original reason for this was to kill the bacteria and lessen the danger when working with pathogenic cultures. At the time the formalin procedure was adopted the flagella on the bacteria under study did not show any difference in appearance as a result of the formalin treatment. The consequent assumption that formalin had no effect on flagellar shape will here be shown to be incorrect. In his Atlas of Bacterial Flagellation (Leifson, 1960) the author described the various flagellar shapes which may be observed in stained preparations of formalin-fixed cultures. The most common shape observed is that of a fairly uniform wave with a wavelength: amplitude ratio of about 4:1. The author labelled this the 'normal' shape. From published darkfield observations such as those of Pijper \& Abraham (1954) and from electronmicrographic studies (Stocker, 1956) it is evident that the usual shape of bacterial flagella is helical. When the flagella dry on the glass surface the helix becomes flattened and the familiar wave shape results. In addition to the normal flagella many bacteria, and most peritrichously flagellate types, may have flagella of wavelength about one half that of the normal flagella. The author has labelled this the 'curly' type. The curly type has also been observed by Pijper in his studies of living bacteria. With many bacteria the normal $\rightarrow$ curly variation appears to have a genetic basis; in others a change of $\mathrm{pH}$ value can cause the change of wavelength. Aside from the normal and curly flagellar shapes the various other recorded shapes such as 'coiled', 'straight', 'small amplitude' and 'undulant' would appear to be mainly a result of formalin fixation. 
Formalin-fixed cultures of several types of bacteria show flagella of the coiled shape. Most Serratia strains show normal flagella in unfixed preparations and coiled flagella in formalin-fixed preparations (Pl. 1, figs. 1, 2). A smaller proportion show curly flagella in unfixed preparations and coiled flagella in formalin-fixed preparations (Pl. 1, figs. 3, 4). The only exception ever observed is a strain of Serratia indica (NCIB 2847) with small amplitude and straight flagella in unfixed preparations, and normal flagella in formalin-fixed preparations (Pl. 1, figs. 5, 6). A strain of Listeria (B-3D) showed coiled flagella in formalin-fixed preparations and normal flagella in unfixed preparations. The same is true for a culture originally labelled Aeromonas liquefaciens (Kluyver L-418) as illustrated in Pl. 1, figs. 9 and 10. A few strains of polar multitrichous pseudomonads have shown coiled flagella in formalin-fixed preparations and normal flagella in unfixed preparations. The flagella of some bacteria may show some coiling in unfixed preparations, but the coiling is invariably enhanced by formalin fixation.

Among peritrichous flagellated bacteria formalin-fixation only rarely produces the straight or small amplitude type of flagella. An example of this is shown in Pl. 1, figs. 7 and 8 with Listeria (B-3A). Incidentally it might be worth noting that this strain of Listeria and one other showing small amplitude flagella are practically non-motile, which indicates some flagellar abnormality. However, bacteria with typical normal flagella after formalin fixation but without apparent motility also exist. Among the polarly flagellate bacteria straight and stiff flagella have occasionally been observed following formalin fixation. Partially straight or undulant flagella are more frequently observed following formalin fixation, particularly among the marine pseudomonads (Pl. 1, figs. 11, 12). These undulant flagella which result from the formalin treatment must not be confused with flagella of long wavelength and large amplitude often found on polarly flagellate bacteria and which are normal for these bacteria.

\section{DISCUSSION}

For the sake of clarity a description of flagellar shape should always include a statement about the method of fixation, whether with formalin or other chemical or none. Preferably both the unfixed and the fixed shapes should be recorded. Formalin fixation is of considerable value in flagellar staining: pathogens are killed; flagella of slime-producing and capsulated bacteria are more readily stained after formalin fixation. The latter is particularly striking with halophilic marine bacteria. The differences in the effect of formalin on the shape of bacterial flagella may have taxonomic significance and the terms 'formalin sensitive' and 'formalin insensitive' may be suggested.

When the flagellar shape is normal or curly after formalin fixation the probability is very small that unfixed preparations will show a different shape. When the flagellar shape is coiled, straight, small amplitude or typically undulant after formalin fixation, the probability is great that the unfixed preparation will show flagella of normal or curly shape. 


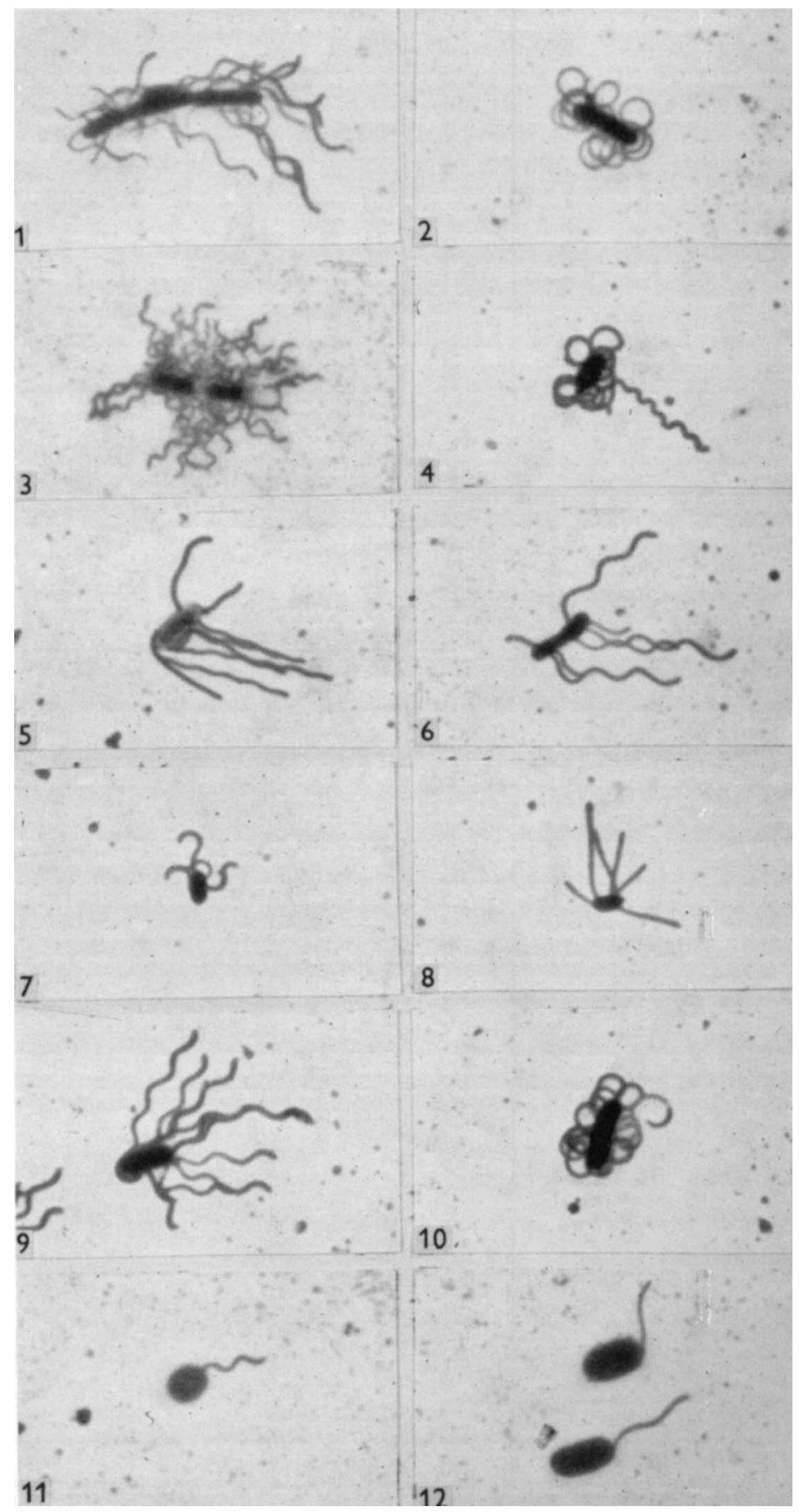




\section{REFERENCES}

Leifson, E. (1960). Atlas of Bacterial Flagellation. New York and London: Academic Press Inc.

Pijper, A. \& Abraham, G. (1954). Wavelengths of bacterial flagella. J. gen. Microbiol. $10,452$.

Stocker, B. A. D. (1956). Bacterial flagella: morphology, constitution and inheritance. In Bacterial Anatomy. Symp. Soc. gen. Microbiol. 6, 19.

\section{EXPLANATION OF PLATE}

Effect of formalin fixation on the shape of the flagella of Serratia and three other types of bacteria. Leifson flagella stain, $\times \mathbf{2 0 0 0}$.

Figs. 1, 2. Serratia kielensis (NCIB 4619). In fig. 1 is shown the unfixed preparation with normal flagella and in fig. 2 the formalin fixed preparation with coiled flagella.

Figs. 3, 4. Serratia marcescens (Smith). In fig. 3 is shown the unfixed preparation with curly flagella. In fig. 4 is shown the formalin fixed preparation with coiled flagella and one curly flagellum.

Figs. 5, 6. Serratia indica (NCIB 2847). In fig. 5 is shown the unfixed preparation with small amplitude and straight flagella and in fig. 6 the formalin fixed preparation with normal flagella. The flagellar shape of this strain of Serratia is unique in the author's experience.

Figs. 7, 8. Listeria monocytogenes (B-3A). In fig. 7 is shown the unfixed preparation and in fig. 8 the formalin fixed preparation. The flagella become straight and stiff as a result of the formalin fixation.

Figs. 9, 10. Aeromonas (Aerobacter) liquefaciens (Kluyver L-418). In fig. 9 is shown the unfixed normal flagella and in fig. 10 the formalin fixed coiled flagella.

Figs. 11, 12. Pseudomonas sp. (halophilic marine type, Colwell). In fig. 11 is shown the unfixed normal flagellum and in fig. 12 the formalin fixed undulant flagella. This is typical of many but not all of marine pseudomonads. 